\title{
O RELATO DE DISCURSO COMO ESTRATÉGIA DE DESENVOLVIMENTO DA COMPETÊNCIA ORAL NO ENSINO-APRENDIZAGEM DO PORTUGUÊS LÍNGUA ESTRANGEIRA ${ }^{1}$
}

\section{EL RELATO DE DISCURSO COMO UNA ESTRATEGIA DE DESARROLLO DE LA COMPETENCIA ORAL EN LA ENSEÑANZA-APRENDIZAJE DEL PORTUGUÉS COMO LENGUA EXTRANJERA}

\author{
REPORTED SPEECH AS A DEVELOPMENT STRATEGY OF ORAL \\ COMPETENCE IN THE TEACHING AND LEARNING PROCESS OF \\ PORTUGUESE AS FOREIGN LANGUAGE
}

\author{
Alexandra FERREIRA ${ }^{2}$ \\ Fátima SILVA ${ }^{3}$
}

RESUMO: Este artigo centra-se na abordagem do relato de discurso enquanto estratégia de desenvolvimento da competência oral de aprendentes de Português Língua Estrangeira (PLE), tendo por base o trabalho desenvolvido no estágio pedagógico numa turma de nível de avançado, no âmbito do Mestrado em Português Língua Segunda/Língua Estrangeira da Faculdade de Letras da Universidade do Porto. O ensino-aprendizagem do relato de discurso oral espontâneo, proveniente, maioritariamente, das interações quotidianas, prevê uma análise que vai para além do plano linguístico e discursivo, o que torna essencial descodificar aspetos paralinguísticos e extralinguísticos que envolvem igualmente competências sociolinguísticas e pragmáticas. Partindo da descrição deste fenómeno linguístico-discursivo, apresentamos o projeto desenvolvido, pormenorizando algumas propostas de operacionalização didática do relato de discurso a partir de documentos autênticos, com base numa abordagem metodológica comunicativa. Os resultados da implementação do plano de intervenção pedagógico-didática realizado mostram que este tipo de abordagem é eficaz no desenvolvimento da competência oral dos aprendentes.

PALAVRAS-CHAVE: Relato de discurso. Competência oral. Oral informal. Abordagem comunicativa.

RESUMEN: Este artículo se centra en el trabajo con el relato de discurso como estrategia de desarrollo de la competencia oral de alumnos de portugués como lengua

\footnotetext{
1 Este artigo tem por base a dissertação de mestrado "Relato de Discurso como Estratégia de Desenvolvimento da Competência Oral em PLE", defendida por Alexandra Ferreira como requisito para a obtenção do grau de Mestre em Português Língua Segunda/Língua Estrangeira, na Faculdade de Letras da Universidade do Porto, em 2015.

2 Faculdade de Letras da Universidade do Porto (FLUP), Porto - Portugal. Formador Externo de Português Língua Estrangeira. ORCID: <http://orcid.org/0000-0002-2439-2091>. E-mail: asferreira@letras.up.pt.

${ }^{3}$ Faculdade de Letras e Centro de Linguística da Universidade do Porto (FLUP), Porto - Portugal. Professora Auxiliar do Departamento de Estudos Portugueses e Românicos. ORCID: <http://orcid.org/0000-0003-2360-5136>. E-mail: mhenri@letras.up.pt.
} 
extranjera (PLE) y tiene como base un trabajo de la práctica de enseñanza en una clase de nivel avanzado en el ámbito del Máster en Portugués Segunda Lengua / Lengua Extranjera de la Facultad de Artes de la Universidad de Oporto. La enseñanzaaprendizaje del relato de discurso oral espontáneo, proveniente, mayoritariamente, de las interacciones cotidianas, prevé un análisis que va más allá de los niveles lingüístico $y$ discursivo, lo que hace esencial descodificar aspectos paralingüísticos $y$ extralingüisticos que implican igualmente competencias sociolingüísticas y pragmáticas. A partir de la descripción de ese fenómeno lingüístico-discursivo, presentamos el proyecto desarrollado, con detalles de algunas propuestas de operacionalización didáctica del relato de discurso a partir de documentos auténticos, teniendo como base un enfoque metodológico comunicativo. Los resultados de la aplicación del plan de intervención pedagógico-didáctica realizado demuestran que este tipo de enfoque es eficaz en el desarrollo de la competencia oral de los alumnos.

PALABRAS CLAVE: Relato del discurso. Competencia oral. Oral informal. Enfoque comunicativo.

ABSTRACT: This paper focuses on the usefulness of reported speech as a strategy to develop the oral competence of learners of Portuguese as a Foreign Language (PLE). It describes an action research work done with a C level class of PLE into the Master of Portuguese as Second Language/Foreigner Language of the Faculty of Arts - University of Porto. The teaching and learning process of spontaneous oral speech report mostly collected from daily interactions revealed that it is essential to decode paralinguistic and extralinguistic aspects that go far beyond the linguistic-discursive level. Apart from the study of the language, the study showed that is essential to know and understand the cultural aspects involving the speech production as a whole. We start by describing that linguistic-discursive phenomenon and by presenting the action research project, detailing some reported speech didactic proposals based on authentic documents, designed using a methodological communicative approach. The results show that the implementation of this type of approach is effective in developing learners' oral competence.

KEYWORDS: Reported speech. Oral competence. Informal oral. Communicative approach.

\section{Introdução}

O presente estudo centra-se no tratamento do relato do discurso como estratégia de desenvolvimento da competência oral no ensino-aprendizagem do Português Língua Estrangeira (PLE) no nível C1, nível de utilizador proficiente autónomo ou avançado (de acordo com a proposta do Quadro Europeu Comum de Referência para as LínguasQECR).

A abordagem deste tópico justifica-se essencialmente por duas razões. 
Por um lado, consideramos que relatar o discurso de outro ou o nosso oralmente é um fenómeno linguístico-discursivo espontâneo e omnipresente no nosso dia a dia, que deve ser trabalhado de forma explícita em contexto de ensino-aprendizagem de uma língua estrangeira (LE), no sentido de desenvolver a competência comunicativa dos estudantes e, especificamente, a sua competência de compreensão, produção e interação orais. A competência oral assume, por conseguinte, particular importância, por exemplo, no âmbito do desenvolvimento de uma relação pessoal e profissional, que exige frequentemente o recurso ao contacto direto através da oralidade, implicando conhecimentos que implicam mais do que o domínio do léxico, da gramática e da pronúncia (competência linguística), pois é necessário aprender as normas socioculturais, sociolinguísticas e discursivas da comunidade linguística.

Por outro, observamos que há ainda bastantes dificuldades no ensinoaprendizagem do relato de discurso em geral, e no relato do discurso oral, em particular, devido à sua elevada idiomaticidade e significação discursiva, sobretudo quando é adotada uma metodologia de natureza mais tradicional, no âmbito da qual se privilegia um tratamento sintático do relato de discurso em detrimento de uma abordagem enunciativo-pragmática (na linha do que é proposto no contexto do ensinoaprendizagem do português por Duarte e Silva (no prelo); e seguido em trabalhos de investigação-ação desenvolvidos por Monteiro (2014) e Lu (2016).

É com base nesta dupla razão que se estruturam a reflexão e a proposta de intervenção pedagógico-didática explanadas neste artigo. Assim, começamos por apresentar o relato do discurso como modalidade estratégica de comunicação oral, tendo em linha de conta algumas caraterísticas do relato de discurso oral, nomeadamente no que se refere às formas do relato na oralidade, com especial incidência nas formas de introdução do relato. Em correlação com esses dados, mostramos a necessidade de implementar uma metodologia de base enunciativo-pragmática na abordagem do relato de discurso, enunciando os seus princípios operatórios. Finalmente, evidenciamos a produtividade desta abordagem através da descrição e discussão de um plano de intervenção pedagógico-didática implementado em sala de aula, no contexto do qual selecionamos, para exemplificação, uma das unidades letivas que o integram.

\section{O relato do discurso como modalidade estratégica de comunicação oral}


De forma genérica, assumimos que o relato de discurso ${ }^{4}$ é um "ato linguístico de reprodução/representação, oral ou escrita, de um discurso pertencente a uma situação enunciativa diversa, passada ou futura, relativamente à enunciação em curso" (MONTEIRO, 2014, p. 7). Isto implica que é condição fundamental para a sua existência a coexistência de, pelo menos, dois planos enunciativos e, consequentemente, duas vozes diferentes - a do locutor citado e a do locutor citante - que mesmo podendo coincidir, pertencem sempre a um plano enunciativo diferente. Assim, o discurso relatado permite a um locutor reproduzir, de diversos modos, outro discurso (de outro locutor ou de si próprio) a um alocutário, que pode coincidir (1) ou não (2) com o locutor original. Este discurso pode já ter sido proferido (3) ou estar previsto (4).

1) Eu disse-te que isso não ia dar bom resultado.

2) Ele disse-me que não nos poderia visitar este ano.

3) A Teresa disse ao Pedro: "Espera para ver o resultado que vais ficar surpreendida!”

4) "Estou super atrasada! Quando chegar a casa, a minha mãe vai dizer: Vais comer a comida fria!"

Aquele que relata não só reproduz como representa o discurso citado, pois nunca é completamente fiel ao discurso original, na medida em que o discurso relatado reflete, de forma mais ou menos percetível, o ponto de vista ou a intenção do relator.

É possível relatar o discurso sob diversas formas, que são enunciadas na distribuição proposta na figura 1 , que consiste numa adaptação a partir da síntese de Monteiro (2014, p. 33), que segue de perto a proposta de Calaresu (2004).

Figura 01: Formas de relatar o discurso com base em Monteiro (2014)

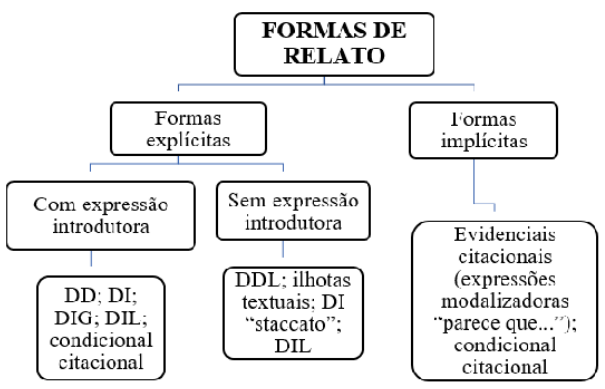

Fonte: Adaptação do quadro de Monteiro (2014, p. 33).

${ }^{4}$ Para uma análise global do discurso relatado, ver, entre outros, Authier-Revuz (1992), Duarte (2003), Marnette (2003) e Mansour (2013). Reyes (2002) centra-se particularmente sobre o DD e o DI. 
Há, por um lado, formas através das quais identificamos explicitamente a reprodução de outro discurso, por exemplo, uma expressão introdutora ou sinais gráficos como as aspas: o discurso direto (DD), o discurso indireto (DI), o discurso indireto glosado (DIG), o discurso indireto livre (DIL), o discurso direto livre (DDL), as ilhotas textuais, o discurso indireto "staccato" e o condicional citacional. Por outro lado, há formas implícitas, em que cabe ao próprio interlocutor reconhecer a existência de dois planos enunciadores diferentes através de uma interpretação das informações pragmáticas e contextuais, nomeadamente através do uso de expressões modalizadoras, do condicional citacional ${ }^{5}$. No trabalho realizado em sala de aula, o foco incidiu sobretudo nas formas de DD e DI, por serem, das mais recorrentes na oralidade.

Além das formas de relato, é necessário considerar outros aspetos que estão interligados e interferem na produção de um relato eficaz, como o contexto enunciativo, a relação entre os interlocutores e o sistema deítico.

O contexto enunciativo é preponderante na sua produção, dado que há implicações pragmáticas que apenas podem ser percetíveis dentro de determinado contexto. Consoante a situação enunciativa, o sistema dêitico e as respetivas referências (pessoais, espaciais e temporais) atualizam-se de múltiplos modos.

Da mesma forma, a relação entre interlocutores assume particular importância no relato do discurso, nomeadamente no relato do discurso oral (MORENO, 2014; DUARTE; CARVALHO,2016).

Enquanto estratégia discursiva, o relato de discurso apropria-se, na oralidade, das características típicas de qualquer discurso oral - partículas modais, construções clivadas, fraseologias, léxico de registo informal, modalizadores de discurso, etc. Neste âmbito, Duarte (2003, p. 14) afirma que:

O discurso (o espontâneo, oral e quotidiano sobretudo e também) constrói-se com uma rede de vozes diferentes, emprega permanentemente citações, quer directa quer indirectamente: também o faz por mera alusão, uso de léxico alheio, de entoações de outros, de ecos (irónicos ou não), de negações, de morfemas argumentativos.

Julgamos que é importante analisar à partida, no relato de discurso oral, o grau de informalidade, presente nas conversas do nosso quotidiano, carregado de elementos que para um não nativo poderão ser difíceis de descodificar, podendo comprometer a comunicação. Duarte e Silva (no prelo) enumeram algumas dessas características:

${ }^{5}$ Em português europeu, ocorre frequentemente o futuro composto na expressão do valor semântico atribuído por Calaresu ao condicional neste quadro. 
o grau de informalidade, as sobreposições de falas, o léxico, a imprecisão ou vagueza da referência ("e tale"), supressões de sílabas ("tás), trocas de sons ("ber", "bou"), modos informais de o locutor se dirigir ao alocutário (man, pá, meu), expressões características do discurso oral mais informal ("tipo" em vez de "como"; "é assim" como marcador de início de exposição; quantificadores informais como "bué de ", "altamente", marcadores discursivos como "olhe", "ora bem".

\section{As formas de relato na oralidade}

Parece haver uma ligação entre a relação entre interlocutores, o grau de formalidade do discurso e as formas preferenciais no relato de discurso. O DD é reconhecido $^{6}$ como a forma de relato mais recorrente na oralidade, sobretudo na interação informal, por permitir recursos como as interjeições, determinados marcadores conversacionais, repetições e frases de tipo exclamativo que, por exemplo, o DI não permite. Além de que estes "artifícios" linguísticos, a par das partículas modais e dos recursos prosódicos, ajudam a mimetizar o discurso oral espontâneo. Duarte (2003, p. 101) afirma que "incluir DD num diálogo oral espontâneo pretende ter como efeito tornar esse relato vivo, presentificá-lo para prender a atenção do interlocutor.”, o que outras formas de relato não conseguem reproduzir:

Recorremos ao DD constantemente numa conversa quotidiana, no relato de um episódio, para representar um momento crucial do quotidiano, de forma a partilhar, com mais detalhe e vivacidade, a experiência relatada com o(s) nosso(s) interlocutor(es), pois o que se pretende é criar o referido efeito de verosimilhança, como se exemplifica nos enunciados 5) e 6).

5) Vejo um carro cheio de cachecóis do Benfica, abro a janela: Vão para o aeroporto? Eles riem-se e eu: Nós também.

6) Tirei uma nota mesmo chunga... já estou mesmo a ver, vou chegar a casa e a minha mãe, com aquela cara: Se tivesses estudado mais...

Em 5), houve com certeza mudanças de entoação ao introduzir o discurso citado, além de, possivelmente, ter sido acompanhado pelo gesto de "abrir a janela", por exemplo, e até por um sorriso ao proferir “Nós também”. Já em 6), o relato antecipado

${ }^{6}$ Calaresu (2004, p. 161) afirma que não existindo dados quantificativos para comprovar esta afirmação, esta crença se deve a dois fatores intuitivos: como o DD é mais evidente do que o DI é mais fácil nota a sua presença; por outro, identificando o DI como forma que recorre à subordinação por natureza, julga-se menos recorrente dado que as estruturas subordinadas são menos recorrentes na oralidade. 
da reação da mãe à nota "chunga" foi acompanhado "daquela cara", zangada e de poucos amigos, e de um tom de voz severo ou de lamento.

Contudo, não podemos ignorar o facto de que, em determinados registos, sobretudo mais formais, o recurso a outras formas de relato como o DI, as expressões citacionais ou até as ilhotas textuais, é também bastante comum na oralidade, como refere, por exemplo, Duarte (2003, p. 108).

Se é verdade que usamos mais DD na conversa informal, certos registos menos familiares desaconselham-no. Será impensável imaginar um relato de discurso feito pelo Primeiro Ministro na televisão, em que ele reproduza, em DD, um enunciado outro. Dirá sempre algo como «Disse hoje ao Senhor Presidente da República que o Governo...etc». Há, portanto, no discurso oral, registos que não preveem o uso de DD, exatamente porque os seus locutores não se podem permitir o recurso ao efeito dramático que o DD provoca. O Dl é tendencialmente mais sóbrio, mais neutro.

Em relação a outras formas de relato, como as expressões citacionais ou o DIL, assumem na oralidade características diferenciadas daquelas que apresentam na escrita. As primeiras, como se pode verificar em 7), assumem um caráter parentético e são anunciadas por uma alteração (diminuição) da entoação com que são produzidas em relação ao resto do discurso. $\mathrm{O}$ segundo, além de permitir a introdução de marcas de oralidade, como, por exemplo os marcadores conversacionais, também é acompanhado por uma alteração de tom, quando se imita, por exemplo, a voz do locutor citado.

7) E toda a gente, alegadamente, abandonou a sala sem arrumar nada, nem o seu próprio copo.

O DDL é também recorrente na oralidade sobretudo quando há vontade expressa de representar um diálogo sob a forma pergunta-resposta. Partilha com outras formas de relato a capacidade de se evidenciar pela alteração de tom. Quanto às ilhotas textuais, partilhamos da opinião de Calaresu (2004) de que são recorrentes na oralidade, mas sobretudo em discursos que permitem uma certa planificação, como o discurso científico e o académico.

\section{As formas de introduzir o relato}

Considerando as duas formas de relato sobre as quais incidiu o nosso trabalho, os verbos introdutores são uma das formas de introdução que assume particular 
importância quer no DD quer no DI, pois, além de integrarem o discurso relatado no discurso que o relata, dão informações sobre o tipo de ato de linguístico representado e sobre a forma como é proferido o discurso e qual é a relação do locutor citante com o locutor citado e o discurso por este realizado. Assim, como afirma Duarte (2001, p.127), "são essenciais para se conhecer a situação de enunciação do enunciado "relatado", com a pluralidade de matizes que inclui (...)".

Esta função pode ser assumida por muitos verbos, tendo sido propostas já várias classificações, com base em critérios diferenciados, nomeadamente sintáticos ou semântico-pragmáticos. Entre essas propostas contam-se as de Charolles (1976), Leech (1983), Bosani (2000) e Duarte (2003), tendo a nossa abordagem do relato de discurso seguido esta última, por se tratar de uma classificação feita especificamente par o português, seguindo critérios semântico-pragmáticos, que se coadunam com os princípios teóricos e metodológicos que defendemos.

Duarte (2003) distingue vários tipos de verbos dicendi, entre os quais verbos de qualificação do dizer (por exemplo, 'indicar', 'revelar', 'balbuciar', 'acrescentar', 'corrigir', 'responder', 'insistir', 'resumir'), verbos assertivos ('afiançar', 'asseverar'), verbos expressivos ('queixar-se'), verbos rogativos ('perguntar', 'pedir', 'inquirir'), verbos diretivos ('aconselhar', 'ordenar', 'reclamar'), verbos perlocutórios ('tranquilizar'), verbos promissivos ('prometer', 'jurar'), verbos que remetem para uma avaliação do locutor ou do alocutário em relação à locução expressa ('confessar', 'reconhecer', 'admitir').

No relato de discurso oral, sobretudo informal, é também muito frequente o recurso a outras formas de introduzir o discurso além dos verbos de comunicação. DUARTE E CARVALHO (2016) e Marques (2015) analisam essas formas, fazendo o levantamento de estruturas muito frequentes e que têm em comum o facto de não existir verbo introdutor, havendo referência ao locutor a quem são atribuídas as palavras.

Duarte e Carvalho (2016) indicam, neste âmbito, estruturas muito frequentes que seguem o seguinte esquema: "e vai + sujeito + DD”, “e + sujeito + DD" e "e + sujeito + para mim + DD”. Trata-se de estruturas que têm em comum o facto de não existir verbo introdutor, havendo referência ao locutor a quem são atribuídas as palavras. Marques (2015), num texto em que aborda o DD em interações orais coloquiais ${ }^{7}$, apresenta

7 "Y llamamos coloquial, entendido como nivel de habla, a un uso socialmente aceptado en situaciones cotidianas de comunicación, no vinculado en exclusiva a un nivel de lengua determinado y en el que 
exemplos de outras sequências que são igualmente frequentes na oralidade, nas quais ocorrem referências ao contexto situacional, aos comportamentos dos participantes e até à interpretação que o locutor faz do discurso que relata, em particular dos atos realizados. Mostra ainda que, na oralidade, surgem outros verbos introdutores que dão conta da presença de uma situação de oralidade coloquial, como é o caso dos verbos 'virar', 'voltar-se' e 'chegar', além de haver situações em que a expressão introdutora se resume a "e eu"/ "e ele", "e vai ela", "e ela assim", "e ela tipo", “e eu do género".

\section{O ensino-aprendizagem do relato de discurso oral nas aulas de LE}

O tratamento do relato de discurso oral no ensino-aprendizagem de uma LE deve basear-se numa abordagem enunciativo-pragmática, integrando não só a competência linguística, mas também a sociolinguística e a pragmática, dado que relatar o discurso de outro ou o nosso, oralmente ou por escrito, que envolve um conjunto de transformações enunciativo-pragmáticas conforme a intenção subjacente ao relato, o contexto enunciativo e a relação entre interlocutores.

Torna-se, por isso, imperativo analisar as características da interação oral e a forma como estas se manifestam numa estratégia discursiva como é o relato; descodificar o sentido destes recursos e os seus efeitos pragmáticos tendo em conta diversos contextos enunciativos, bem como diversos registos (formal, informal ou coloquial $)^{8}$; e avaliar a relevância dos aspetos prosódicos, já que, por exemplo, uma diferente entoação poderá ser suficiente para anunciar a mudança de plano enunciativo.

No nosso trabalho de operacionalização deste conteúdo em sala de aula seguimos a metodologia de base enunciativo-pragmática proposta por Duarte e Silva (no prelo), que segue as etapas enunciadas na figura 02.

Figura 02: Princípios pedagógico-didáticos na abordagem do discurso relatado

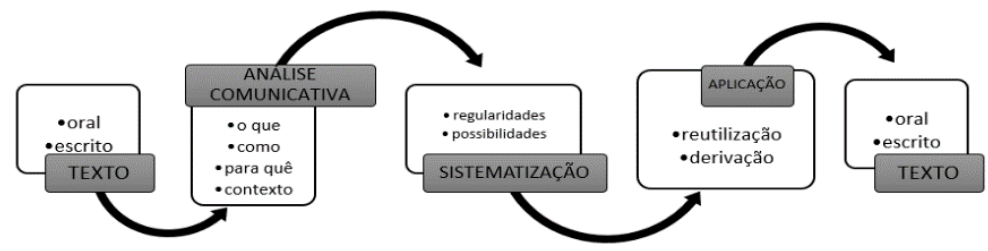

Fonte: Adaptado de Duarte e Silva (no prelo).

vulgarismos y dialectalismos aparecen en función de las características de los usuarios” (BRIZ, 2010, p. 26).

${ }^{8}$ Cf., neste domínio, os trabalhos de Aufray (2008), Caillat (2013) e ainda Duarte (2006). 
A abordagem do relato do discurso deve, de acordo com Duarte e Silva (no prelo), primeiro que tudo, prever uma abordagem linguístico-discursiva vinculada a uma perspetiva acional e comunicativa de ensino-aprendizagem, pois só assim é possível descrever a língua em uso, em situação de comunicação, expondo os estudantes a produtos orais variados.

Desta forma, revela-se preponderante o recurso a materiais autênticos que além de constituírem amostras de língua em situação real são mais motivadores para os nossos estudantes. No caso específico do tratamento do relato de discurso oral, Duarte e Silva (no prelo) defendem que a audição de gravações de textos orais autênticos (conversas autênticas, conversas de registo relativamente informal incluídas, por exemplo num programa de rádio ou televisão ou até conversas provenientes de ficção como no cinema ou programas humorísticos) se revelam de extrema importância no desenvolvimento da competência dos aprendentes na produção oral ou escrita do que é ouvido.

Este tipo de textos são habitualmente ricos em termos linguístico-discursivos para a aprendizagem da "informalidade da conversa quotidiana" (DUARTE, 2015, p.61), proporcionando o contacto com diferentes registos e variedades, tornando mais rico o input linguístico e discursivo, evitando uma excessiva simplificação e/ou estilização, porque os aprendentes contactam com a complexidade da língua em uso.

Por fim, e não menos importante, é a integração deste conteúdo noutras atividades de compreensão e produção, assim como de funcionamento da língua. Só desta forma se promove o fim último de qualquer intervenção didática: $o$ desenvolvimento da competência comunicativa dos estudantes.

Assim, a abordagem integra-se numa pedagogia do oral que procura preparar os estudantes para situações de uso real da língua, através da implementação de atividades e estratégias variadas, possibilitando o contacto com uma multiplicidade de situações de produção quotidiana com recurso a documentos reais, condições apontadas, entre outros, por Duarte (2015) para o lugar de destaque que deve dar-se à competência oral no ensino-aprendizagem de uma língua estrangeira.

Nesse contexto, a abordagem tradicional do relato de discurso manifesta-se claramente insuficiente, sobretudo em situações pedagógico-didáticas em que a transposição de relato é feita de forma mecânica e descontextualizada, propondo-se somente algumas alterações morfossintáticas, sem referência à situação enunciativa nem 
ao discurso citador ${ }^{9}$, o que subestima, por exemplo, a quantidade de possibilidades à disposição do falante para efetuar um relato e a variedade de aspetos estruturais e funcionais a considerar nas várias formas de relato,

Na sequência da fundamentação da proposta de uma pedagogia do relato de discurso na sua modalidade oral, promotora da competência comunicativa dos estudantes de PLE, proceder-se-á, de seguida, à descrição do trabalho desenvolvido em sala de aula.

\section{O ensino-aprendizagem do relato de discurso oral numa turma de Português Língua Estrangeira}

\section{Plano de intervenção pedagógica: contexto}

Com base nos princípios teóricos subjacentes à consideração do relato do discurso como modalidade estratégica de comunicação oral e a uma abordagem deste conteúdo seguindo uma metodologia de base acional, com a finalidade última de promover o desenvolvimento da competência oral dos estudantes, foi operacionalizado, no contexto do $2^{\circ}$ ano do Mestrado em Português Língua Segunda/Língua Estrangeira da Faculdade de Letras da Universidade do Porto, no contexto do estágio pedagógico, um plano de intervenção pedagógico-didática, que teve como público uma turma de nível C1 do segundo semestre do Curso Anual de Português para Estrangeiros.

A turma era constituída por 7 estudantes em imersão, com idades compreendidas entre os 22 e os 36 anos de idade, oriundos de Espanha, Noruega, Itália, Japão, China e Venezuela. A maioria deles dominava, pelo menos, duas línguas estrangeiras, com dominância para o inglês e o espanhol.

\section{Plano de intervenção pedagógica: objetivo e metodologia}

O trabalho realizado teve como finalidade central desenvolver a competência oral dos estudantes através da abordagem do relato de discurso oral, sobretudo informal.

\footnotetext{
${ }^{9}$ A insuficiência de uma abordagem exclusivamente deste tipo é discutida por Duarte e Silva (no prelo), Monteiro (2014) e Lu (2016). Dado que, no nosso trabalho, este modelo não foi o usado, a não ser no contexto do teste diagnóstico ministrado aos estudantes no início do tratamento do relato de discurso, em paralelo com exercícios que solicitavam mais a competência linguístico-discursiva dos aprendentes, consideramos dispensável a sua análise alargada neste contexto.
} 
Na planificação do trabalho a implementar em sala de aula, foi estabelecido um esquema concetual, que guiou o percurso de intervenção pedagógico-didática. Esse esquema, constituído por seis etapas, está sintetizado na figura 03.

Figura 03: Síntese do plano de intervenção pedagógico-didática

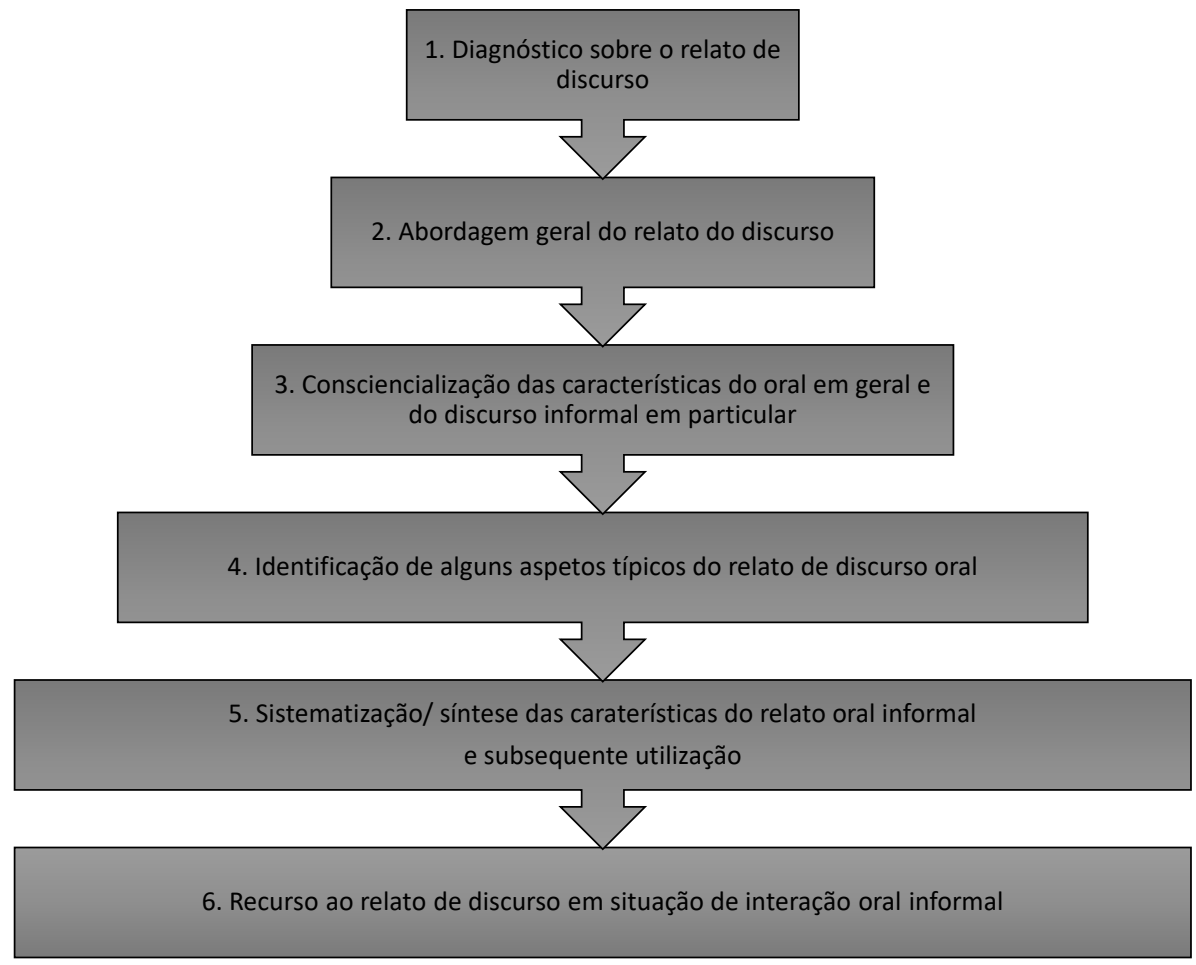

Fonte: Autoria própria.

O desenvolvimento deste plano e a proposta de um conjunto de atividades variadas que fossem ao encontro dos interesses e necessidades dos aprendentes teve como base os resultados de uma diagnose inicial, que consistiu no preenchimento de um inquérito para caracterização dos estudantes e identificação das suas dificuldades e na realização de uma tarefa de diagnóstico sobre o conhecimento prévio dos estudantes, explícito e implícito, relativamente ao relato do discurso.

Com base nestes resultados, delineou-se, então, o plano de intervenção pedagógico-didática, no qual foram etapas relevantes a fundamentação do plano propriamente dito, o estabelecimento de objetivos e a proposta de atividades, tarefas e materiais didáticos, bem como a sua execução em sala de aula.

Não sendo nossa intenção, neste artigo, discriminar de forma pormenorizada a implementação de todas as etapas, incidimos centralmente sobre as atividades realizadas em sala de aula, que é necessário enquadrar tendo em consideração o percurso acional 
no seu todo. Assim, a nossa proposta para o tratamento do relato de discurso oral informal assentou na recolha de um corpus de material autêntico - conversas entre nativos, programas televisivos ou radiofónicos - pedagogicamente motivador e adequado à turma-alvo, que permitisse a análise dos respetivos recursos linguísticos e discursivos relevantes na abordagem do relato. $\mathrm{O}$ tratamento desse corpus no contexto de sala de aula foi mediado por atividades de receção e produção orais, seguindo um modelo acional de tratamento do relato do discurso.

\section{Descrição de uma unidade letiva implementada}

Apresentamos, de seguida, uma das unidades letivas lecionadas no sentido de ilustrar de forma mais clara os princípios metodológicos enunciados e o trabalho desenvolvido. Embora tenhamos a consciência de que se trata apenas de uma parte do trabalho desenvolvido e, por conseguinte, de uma parte incapaz de representar a percurso no seu todo, considerámos pertinente mostrar de forma mais pormenorizada o trabalho proposto aos estudantes ao longo das sete sessões, num total de $14 \mathrm{~h}$, que constituíram este trabalho de estágio.

\section{Objetivos da unidade letiva}

A unidade letiva apresentada, com a duração de $2 \mathrm{~h}$, cujo conteúdo temático principal era o turismo em Portugal, tinha como objetivos gerais compreender textos orais de registo informal; reconhecer estratégias linguísticas do relato de discurso oral informal e produzir textos orais em diferentes contextos. A estes objetivos gerais correspondiam os seguintes objetivos específicos: analisar o conteúdo de uma reportagem televisiva; descodificar estratégias linguístico-discursivas no relato de discurso oral; produzir um relato de discurso oral informal; resumir o conteúdo de uma rubrica de rádio; sistematizar as caraterísticas típicas do relato de discurso em termos de formas de relato, introdução do relato e recursos paralinguísticos; e relatar as palavras do colega.

\section{Sequenciação das atividades propostas}

Para o cumprimento destes objetivos foi proposta a sequenciação didática que se apresenta no quadro 01 . 
Quadro 01: sequenciação das atividades propostas na unidade letiva descrita

Sequenciação das atividades propostas na unidade letiva Turismo em Portugal

1. Visualização de uma reportagem da TVI sobre a Estação de S. Bento,

1.1 Análise do conteúdo da reportagem através de um exercício de verdadeiro e falso com correção de questionário oral dirigido.

2. Exercício de relato de discurso realizado a pares,

2.1 Visualização de um momento da reportagem e análise do discurso dos interlocutores;

2.2. Redação do relato do diálogo entre os interlocutores.

3. Exercício individual sobre a opinião dos estudantes relativamente a alguns locais emblemáticos da cidade do Porto: produção de frases conforme o exemplo dado

4. Audição de uma rubrica da Rádio Comercial cujo tema é "O turista mais chato do mundo". 4.1 $1^{\text {a }}$ audição com o objetivo de realizar um exercício de preenchimento de espaços de um pequeno texto que resume a rubrica - correção através de questionário oral dirigido;

$4.22^{\mathrm{a}}$ audição com o objetivo de analisar um momento do relato do discurso oral: os estudantes deverão identificar as características típicas deste relato: em termos de formas de relato, a introdução do discurso, o recurso a diferenças de tom e ao volume ou intensidade que produz vários efeitos paralinguísticos.

5. Apresentação oral: através de um póster os estudantes farão a promoção da sua cidade ou da sua região.

5.1 Apresentação individual com recurso a um póster de promoção turística;

5.2 Exercício de relato de discurso oral: cada aluno deverá eleger a apresentação mais convincente defendendo a sua escolha relatando partes do discurso do respetivo "promotor".

Fonte: Autoria própria

O ponto de partida foi a visualização e análise de uma reportagem televisiva sobre a Estação de S. Bento. Feita a análise do seu conteúdo através de um exercício de verdadeiro/ falso, seguiu-se um momento de análise linguístico-discursiva de parte da reportagem em que são entrevistadas duas transeuntes:

Transeunte A: Conheci quem fez isto!

Repórter: Foi?

Transeunte B: $O$ arquiteto Marques da Silva.

A: Como é que ele se chama? O...

B: Marques da Silva. 
A: Marques da Silva.

Repórter: Gostou da obra dele? Gosta!

A: (acena com a cabeça)

a. Conheci quem fez isto - O pronome isto refere-se:

$\square$ à reportagem

$\square$ à Estação de S. Bento

b. Foi? - Esta interrogação serve para:

questionar o nome de quem fez "aquilo"

confirmar a veracidade da afirmação anterior

c. Como é que ele se chama? - Esta questão é feita:

$\square$ ao repórter

$\square$ à amiga

d. Como é que ele se chama? O... - Esta intervenção denota que:

$\square$ a senhora não sabe o nome do artista

$\square$ a senhora não se lembra do nome do artista

e. Marques da Silva. - A transeunte A repete a resposta porque:

$\square$ não quer que a amiga fale com o repórter

$\square$ quer responder diretamente ao repórter

f. Gostou da obra dele? Gosta! - O repórter corrige o tempo da forma verbal porque:

$\square$ o arquiteto ainda é vivo

o ato de gostar é atual

g. Gostou da obra dele? - A transeunte A:

$\square$ não responde à pergunta

$\square$ responde sem verbalizar 
h. Gostou da obra dele? - A transeunte A responde:

positivamente

negativamente

Ao analisarem este pequeno diálogo entre o jornalista e as duas entrevistadas, os estudantes deram-se conta de algumas características típicas do discurso oral informal, tais como: repetições, hesitações, correções e reformulações, pausas, mudanças de tom, gestos e outro tipo de linguagem não verbal, interjeições, marcadores e outras partículas da oralidade. O objetivo era que, depois de analisarem detalhadamente o diálogo e descodificarem o significado e o valor desses elementos, ficassem habilitados a reproduzir sob a forma de relato o diálogo.

O exercício de relato de discurso foi realizado em dois grupos. Cada grupo registou a sua versão do relato do diálogo num acetato para que depois pudesse comparar os dois textos com maior facilidade. O resultado foi que, graças à análise feita previamente e à abordagem realizada em unidades didáticas precedentes, os textos revelaram-se bastante similares e os estudantes não revelaram grandes dificuldades. Vejamos os dois textos produzidos:

\begin{tabular}{|c|c|}
\hline & \\
\hline $\begin{array}{l}\text { Um repórter da TVI fez uma } \\
\text { entrevista a uma senhora na estação de } \\
\text { S. Bento e ela disse que conhecia que a } \\
\text { tinha feito mas não se lembrava do nome } \\
\text { dele. Foi a amiga que estava com ela que } \\
\text { respondeu à pergunta e disse que foi o } \\
\text { Marques da Silva. O repórter perguntou } \\
\text { se gostava da obra dele e a senhora } \\
\text { afirmou acenando a cabeça } \\
\text { positivamente. }\end{array}$ & $\begin{array}{l}\text { Nestas entrevistas duas } \\
\text { portuguesas foram entrevistadas por um } \\
\text { repórter. Uma dessas portuguesas disse } \\
\text { que sabia quem tinha construído a } \\
\text { estação de S. Bento, mas não lembrava o } \\
\text { nome do artista e pediu à amiga uma } \\
\text { ajuda. Ela relembrou-lho. Em seguida, o } \\
\text { repórter perguntou se ela gostava da } \\
\text { obra dele e ela acenou a cabeça sem } \\
\text { hesitar. }\end{array}$ \\
\hline
\end{tabular}

O resultado do relato do discurso é muito próximo nos dois textos e ambos são bastante fiéis à entrevista ouvida e visualizada.

Seguindo a mesma linha, os estudantes começaram por analisar o conteúdo de uma rubrica de rádio, completando espaços de um texto que coincide com o seu resumo. 
Nesta rubrica, com o título "O turista mais chato do mundo", o locutor relata aquilo que anuncia serem frases inusitadas que alguns turistas proferiram quando visitaram certos monumentos e/ou destinos mundialmente famosos:

\section{a. Leia as frases que seguem, antes da segunda audição:}

i. Há um tipo que foi ao Gran Canyon e disse: "Hum... Não achei nada de especial."

ii. Torre Eiffel. Exlibris de Paris. Comentário de um, um utilizador do Trip Advisor: "A vista é boa para quem gosta de ver as vistas. Agora, o café é péssimo."

iii. Cataratas do Niagara: "Não tem nada a ver com as fotografias que vimos. Os estrangeiros que lá estavam entraram em todas as fotografias que tirámos. Foi muito chato! Achámos toda a experiência aborrecida com hambúrgueres demasiado caros."

iv. O melhor comentário de todos é: "Estátua da liberdade: Não gostei. É só uma estátua."

v. Houve alguém que foi ao Taj Mahal e diz: "Mais vale ver a fotografias na net estava muito calor."

vi. $\quad$ À ópera de Sydney, onde tu já foste, Vanda (...) diz que quanto mais longe estiver do edifício mais bonito ele fica. "Não é nada de especial; é mais bonito na televisão."

vii. Machu Picchu: "Não vale o esforço de lá ir; é muito cansativo."

viii. Muralha da China: "Odiei. Estava nevoeiro. Foi um desperdício."

ix. Depois, o Angkor Wat (...) as pessoas: "Não, não, não. A construção tava muito rasca."

\section{b. Ouça novamente a rubrica, concentrando-se nas frases citadas.}

\section{c. Contextualize estas frases.}

\section{d. Identifique características típicas do relato de discurso oral.}

Ao analisarem este relato, os estudantes foram capazes de enumerar as marcas mais evidentes do relato de discurso oral:

- recurso ao DD como forma de relato preferencial;

- omissão do verbo introdutor e opção por outras formas de introdução de relato; 
- recurso a determinados artifícios prosódicos, como as alterações de tom, volume ou intensidade da voz usados no momento em que se passa as palavras que são relatadas.

Depois de os próprios estudantes concluírem e enumerarem estas características, foi construída uma ficha síntese, na qual se tiveram em consideração não só as conclusões da unidade letiva descrita como também todo o trabalho feito anteriormente, nomeadamente através da convocação de exemplos práticos trabalhados, em termos de receção e produção. Além das formas de relato de discurso encontradas no trabalho desenvolvido, os estudantes enumeraram as formas mais recorrentes do relato de discurso oral informal, que se encontram indicadas no quadro 02.

Quadro 02: Formas recorrentes de introdução do relato de discurso oral informal

\begin{tabular}{|c|c|}
\hline Introdução & Exemplo \\
\hline $\begin{array}{l}\text { Sujeito }+ \\
\text { verbo "ser": }\end{array}$ & $\begin{array}{l}\text { "O melhor comentário de todos é: Estátua da liberdade: Não } \\
\text { gostei. É só uma estátua." }\end{array}$ \\
\hline $\begin{array}{l}\text { Referência ao } \\
\text { locutor do discurso } \\
\text { relatado, através de } \\
\text { um nome, substantivo } \\
\text { ou pronome }\end{array}$ & $\begin{array}{l}\text { "E a Catarina: Nem pensar!” } \\
\text { "Depois, o Angkor Wat (...) as pessoas: Não, não, não. A } \\
\text { construção tava muito rasca." } \\
\text { "E eu: Não, não, isto é uma desfeita muito grande!; e eles: } \\
\text { Olha que não!” }\end{array}$ \\
\hline $\begin{array}{l}\text { Referência } \\
\text { contextual }\end{array}$ & $\begin{array}{l}\text { Machu Picchu: "Não vale o esforço de lá ir; é muito } \\
\text { cansativo." }\end{array}$ \\
\hline $\begin{array}{l}\text { Advérbios, } \\
\text { preposições ou } \\
\text { locuções adverbiais }\end{array}$ & $\begin{array}{l}\text { "Oh Vasco, queres estar calado?”; } \\
\text { Às vezes: “Dr. Mesquita, leite gordo ou meio gordo?”, }\end{array}$ \\
\hline $\begin{array}{l}\text { Verbos } \\
\text { movimento }\end{array}$ & $\begin{array}{l}\text { Voltou-se: "Ai eu é que não vou”; } \\
\text { O meu pai virou-se: "Ai vais, vais!”; “ } \\
\text { A Sara chega: "Podes sair daí para eu imprimir?" }\end{array}$ \\
\hline Orações & $\begin{array}{l}\text { "Já sente algum gozo naquela antecipação: Será que eu vou } \\
\text { conseguir?" }\end{array}$ \\
\hline
\end{tabular}

Fonte: Autoria própria

Os estudantes prepararam em casa, a partir das instruções dadas previamente e de um exemplo prático, um folheto (em formato digital) para promover a sua cidade ou 
região. Depois, fizeram uma apresentação oral para descrever o conteúdo do folheto. Os colegas, por sua vez, avaliaram a apresentação e atribuíram uma pontuação a vários parâmetros definidos numa grelha. Cada aluno selecionou aquela que foi, na sua opinião, a melhor apresentação e justificaram relatando partes do discurso do colega. Foi a simulação de uma situação de relato oral informal, neste caso, com o objetivo de atestar a escolha de cada um. Alguns dos enunciados produzidos pelos estudantes correspondem aos exemplos (8) - (11):

8) "Eu gostei especialmente, porque ele disse: é um local multicultural!"

9) "E por fim: é uma cidade que vale a pena visitar"

10) "A parte de que eu mais gostei foi: é um lugar cheio de luz."

11) "Achei engraçado: “em cada canto há alguma coisa nova para descobrir".,

\section{Alguns resultados da implementação do plano de intervenção pedagógico-didática}

A implementação do plano de intervenção pedagógico-didática descrito, centrado na abordagem do relato de discurso como estratégia de comunicação oral teve resultados globalmente positivos, na medida em que, no final do percurso realizado, oes estudantes eram capazes de:

- reconhecer e identificar diferentes mecanismos implicados no discurso relatado do ponto de vista linguístico-discursivo, nos registos oral e escrito, mas com especial incidência no texto oral, sobretudo em contexto informal;

- compreender o relato de discurso como uma estratégia recorrente nas transações orais;

- descodificar estratégias linguístico-discursivas e reconhecer características típicas do relato de discurso oral a partir da análise de discursos orais autênticos, com capacidade para se adequar às coordenadas da situação enunciativa em contextos diversos;

- produzir textos orais e interagir de forma mais próxima dos contextos reais de uso do português.

Revelou-se essencial, neste ponto, o recurso a materiais autênticos. O contacto com produtos orais reais é essencial no desenvolvimento da competência dos estudantes. Não só permite aceder a diferentes registos e variedades da língua, como também, e essencialmente, ao contacto com a língua em situação de uso, onde as regras 
gramaticais apresentam regularidades diferentes das da escrita e outras dimensões da língua adquirem particular importância, nomeadamente a linguagem corporal e os sinais prosódicos.

Os exercícios e as atividades foram sendo organizados num crescendo de complexidade, pois era importante desenvolver a autonomia dos estudantes: de início as atividades eram mais orientadas e no final criaram-se situações que promovessem a sua iniciativa e criatividade.

Por outro lado, o trabalho sistemático e explícito, associado ao recurso ao conhecimento implícito dos estudantes, sobre este tópico constituiu igualmente um fator relevante nas várias fases do trabalho, nomeadamente ao nível do reconhecimento, da análise, da sistematização e da aplicação, envolvendo da parte dos estudantes um saber e um saber fazer no âmbito das diferentes competências comunicativas.

Apesar dos resultados positivos enunciados ao nível dos resultados de aprendizagem dos estudantes, várias questões se colocaram ao longo do percurso efetuado, de entre as quais destacamos as seguintes:

- o relato do discurso é um conteúdo difícil de trabalhar, por abarcar questões muito diversas, ao mesmo tempo que exige que, professor e estudantes, façam uso do seu saber e do saber fazer em variadas dimensões;

- trabalhar a oralidade dentro da sala de aula dificulta a criação de situações completamente espontâneas de produção de relato;

- selecionar materiais autênticos para o tratamento deste conteúdo é uma tarefa árdua e nem sempre completamente satisfatória, dada a dificuldade em conciliar os temas das unidades didáticas com a necessidade de exemplares significativos para o tratamento do objeto de trabalho.

\section{Considerações finais}

O tema estruturador do trabalho desenvolvido no âmbito do estágio pedagógico do Mestrado em Português Língua Segunda/Língua Estrangeira esteve na base na implementação de um plano de intervenção pedagógico-didática centrado no relato de discurso como estratégia de comunicação oral e tendo como principal objetivo o desenvolvimento da competência oral dos aprendentes da turma no qual foi implementado. Trabalhar este conteúdo na sua modalidade oral implicou que o projeto desenvolvido tivesse uma dupla vertente, a da investigação e a da ação. No que se refere 
à primeira, procedemos à delimitação de algumas caraterísticas do relato do discurso, sobretudo ao nível oral, informal, tendo em conta as suas formas e funções. Nesse contexto, assumimos, conhecendo várias possibilidades para a sua abordagem, uma metodologia de base enunciativa e linguístico-discursiva, por considerarmos que o relato de discurso, pelas suas caraterísticas, deve ser trabalhado atendendo às diversas variáveis que nele interagem e não apenas de um ponto de vista estritamente linguístico.

Esta necessidade representa um desafio para o professor, ao qual que tenha um saber e um saber fazer capaz de lidar com um conteúdo relevante para o desenvolvimento da competência oral dos aprendentes, mas também difícil, pelas diferentes possibilidades que se abrem ao seu tratamento e a abrangência da sua realização. Junta-se a este desafio a necessidade de integrar o tratamento do relato de discurso oral, sobretudo informal, no âmbito de uma pedagogia do oral cuja finalidade é ativar diversos conhecimentos que tornam um falante e/ou ouvinte de uma língua estrangeira em sucedido na sua atividade linguística.

AGRADECIMENTOS: CLUP - UID/LIN/00022/2016 (Fundação para a Ciência e a Tecnologia) e Programa «Reitoria da Universidade do Porto/.

\section{REFERÊNCIAS}

AUFRAY, A. Cadre théorique pour une étude du discours rapporté à l'oral en allemande. In: Dialogues interlinguistiques - Recueil des jeunes chercheurs du CELTA, Paris: Sorbonne, 2008.

AUTHIER-REVUZ, J. Repères dans le Champ du Discours Rapporté. L'Information Grammaticale, 55, 1992, p. 38-42.

BOSANI, A. Verbos de comunicación y discurso. In TOVAR, J. et alli. (eds.), Lengua, discurso, texto (I Simposio International de Análisis del Discurso). Madrid: Visor Libros, v. I, p. 253-261, 2000.

BRIZ, A. El español coloquial: situación y uso. Madrid: Arco Libros, 2010.

CAILLAT, D. Le discours rapporté direct à l'oral: gestion multimodale de l'insertion d'un discours autre. In: DESOUTTER, C.; MELLET, C. (dir.). Le discours rapporté: approches linguistiques et perspectives didatiques. Berna: Peter Lang, 2013.

CALARESU, E. Testuali Parole: la dimensione pragmatica e testuale del discorso riportato. Milão: FrancoAngeli, 2004. 
CHAROLLES, M. Exercices sur les Verbes de Communication. Pratiques, 9, p. 83107, 1972.

\section{CONSELHO DA EUROPA. Quadro Europeu Comum de Referência para as Línguas. Aprendizagem, ensino, avaliação. Porto: Asa, 2001.}

DUARTE, I. Do saber ao ensinar: em torno dos verbos introdutores de discurso relatado. In: FONSECA, F. I.; DUARTE, I.; FIGUEIREDO, O. (orgs.). A linguística na formação do professor de português, Porto: CLUP, 2001, p. 125-134.

DUARTE, I. O relato de discurso na ficção narrativa: contributos para a análise da construção polifónica de Os Maias de Eça de Queirós. Lisboa: FCG, 2003.

DUARTE, I. Venez, venez!" : de la suggestion à l'injonction dans les langues romanes. In: CARREIRA, M. H. (dir.).Travaux et Documents. Paris: Université Paris 8, 2006, p. $155-176$.

DUARTE, I. Textos orais: Análise da conversa informal e ensino do Português Língua Estrangeira. Todas as Letras, v. 17, n. 1, p. 56-72, 2015.

DUARTE, I.; CARVALHO, A. Discours rapporté dans l'oral informel: 1'imprécision. In A. Berrendonner, M.-B. Mosegaard Hansen, R. P. Zafiu (Éd.), Actes du XXVIIe Congrès international de linguistique et de philologie romanes (Nancy, 15-20 juillet 2013). Section 10: Linguistique textuelle et analyse du discours. Nancy, 2016.

DUARTE, I.; SILVA, F. (no prelo). Revisitação do discurso relatado no ensinoaprendizagem do PLE. In: CIAMA, A.; TELETIN, A. (ed.). Tempo, Espaço e Identidade na Cultura Portuguesa: desafios e perspetivas (2 vols.). București: Ed. Universității din București.

FERREIRA, A. O relato de discurso como estratégia de desenvolvimento da competência oral em PLE. (Dissertação de Mestrado em Letras), Faculdade de Letras da Universidade do Porto, Porto, 2015.

LEECH, G. Principles of pragmatics. Londres e Nova Iorque: Longman, 1983.

\section{LU, S. O ensino do relato de discurso numa turma de Português Língua}

Estrangeira do nível B1. (Dissertação de Mestrado), Faculdade de Letras da Universidade do Porto, Porto, 2016.

MANSOUR, L. Discours direct et représentation de la parole intérieure. In: DESOUTTER, C.; MELLET, C. Le discours rapporté: approches linguistiques et perspectives didactiques. Berna: Peter Lang. 2013.

MARNETTE, S. Aux frontières du discours rapporté. Revue Romane, 37, p. 3-30, 2002.

MARQUES, M. A. O discurso relatado em interações orais coloquiais. In: MARQUES, M. A.; REI, X. M. S. Novas perspetivas linguísticas no espaço galego- português. 
Revista Galega de Filoloxia, Monografia 10, Consorcio Editorial Galego, 2015, p. 89109.

MONTEIRO, N. O relato de discurso no ensino do PLE: um caso em estudo.

(Dissertação de Mestrado), Faculdade de Letras da Universidade do Porto, Porto, 2014.

MORENO, A. Le discours rapporté dans l'interaction: proximité et variabilité. In

Congrès Mondial de Linguistique Française - CMLF, p. 1685-1699, 2014.

REYES, G. Los procedimientos de cita: estilo directo y estilo indirecto. Madrid: Arco Libros, 2002.

\section{Como referenciar este artigo}

FERREIRA, A.; SILVA, F. O relato de discurso como estratégia de desenvolvimento da competência oral no ensino-aprendizagem de Português Língua Estrangeira. Rev. EntreLínguas, Araraquara, v.4, n.1, p. 58-80, jan./jun., 2018. E-ISSN: 2447-3529. DOI: $10.29051 /$ rel.v4.n1.2018.10988

Submetido em: 30/01/2018

Aprovado em: 05/03/2018 